from the HSC and reinstated in their former guises. Attempts to have the Alkali and Clean Air Inspectorate returned to the Department of the Environment have also met with little success. But this should come as no surprise, for few governments would wish to see their own creations dismembered so early in life, and the HSC. is after lal a protegé of a Labour government, albeit its second term in office.

It remains to be seen whether future British governments take the demands for dismemberment more seriously. By that time, however, most of the arguments in favour of such a measure will no longer apply, for the various in- spectorates will be more coordinated, and existing and proposed legislation will be more in tune. As for the 1974 HSW Act, the results of that legislation can only be judged some years from now. Many are in no doubt that the Act will be shown to have achieved its objective, that is, a safer working environment in the UK.

\title{
Protecting production or workers?
}

In November 1974, the British Society for Social Responsibility in Science reported in Nature on its work on vinyl chloride monomer. The Work Hazards Group of BSSRS sent Nature this update of its activities:

OVfr the past three years, BSSRS has expanded its hazards programme with the aim of providing information to those directly at risk on the factory floor and to community groups directly affected by industrial hazards. We now publish Hazards Bulletin five times ycarly which includes material on particular hazards, developments in health and safety legislation, legal cases and trade union struggles for health and safety in the workplace. Pamphlets on noise, oil, vibration and asbestos dust provide more comprehensive analyses of the effects of these hazards and how to fight them. Our hazards enquiry service now receives 50-75 enquiries per month. Local hazards groups work within trades councils, local trade union branches and community groups on health and safety issues, and we talk directly to safcty representatives and shop stewards on day release safety training courses organised by concerned members of the trade union movement. This direct contact has been invaluable to our work.

While we have been developing our work at the rank and file level, worldwide concern about environmental hazards has increased. The enormity and horror of the disasters at Flixborough and Seveso, the struggle of the inhabitant of Minimata Bay to obtain compensation for the damage done by mercury poisoning, the poisoning of the state of Michigan by PBB, the militant demonstrations against fission reactors in France, West Germany and the United States, have all forced the scientific communities in industry and the universitie to begin a more systematic evaluation of the hazards of old and new technologies So far. unfortunately, this response has been grossly inadequatc, reflecting a remoteness from the problem and a lack of fundamental concern for those who are directly at risk.

A conference on risk held at Impcrial Collcge, London, last May and organised bv the Council for Science and Society (CSS) and the ensuing leaders and articles in Nature (19 May, 26 May) expressed fundamental differences of approach between our work and current academic and industrial considerations. The dominant note struck at the CSS conference and echoed in the pages of Nature is the need to guarantee production. Health and safety issues arc secondary to the needs of maintaining and increasing production. Whilc this approach is understandable from the point of view of those responsible for planning the economy it is unaccept- able to those directly at risk in the factories and the neighbouring communities. Significantly, trade unionists and community groups are virtually excluded from conferences such as the one organised by CSS where the issues are discussed and where policy begins to be formulated.

Aside from the inexcusable absence of those directly affected by the discussions and the decision making, there are fundamental problems when the emphasis is on guaranteeing production first and safety second. Such protection as is provided involves enclosing the worker in cheap protective clothing rather than enclosing or redesigning the production process itself. Industry sees the problem as protecting the operation and design of the process, an attitude which characterises a number of industrial approaches to health and safety.

The first approach is a reluctance to accept that a hazard exists. The asbestos industry still claims that there is no risk to the general public from asbestos (remarks of Alex A. Cross, chairman, standing committee. International Asbestos Information Conference at Asbestos Information Association Third Annual IndustryGovernment Conference, September 8-9. 1976). The second approach is to accept that a hazard does exist but that it is small. This leads to the notion of acceptable risk and threshold limit values (Hazards Bulletin 7, July 1977) in an effort to quantify the argument. In the case of asbestos, standards are set at 2 fibres per cc, which is a factor of ten greater than that demanded by the trade unions representing the majority of workers exposed to asbestos. Our evaluation of the literature leads us to give unqualified support to this very minimal trade union demand and we have urged trade unions to ban asbestos and get it replaced with the numerous safer alternatives that are commercially available (The Ashestos Hazard. Birmingham Hazards Group, 67 Woodstock Road, Birmingham 13).

$\Lambda$ third argument employed when faced with an apparent contradiction bctween production and safety is to compare the risk with other already existing dangers. The use of fatal accident frequency rates (FAFR) frames this approach. According to FAFR statistics, which ignore occupational disease. non-fatal crippling accidents, the effects of shift work and other debilitating hazards, mining is less hazardous than driving a car. Such an argument paints a picture of the public as being irrational in opposing one hazard while seeming to accept another without protest. The Nature leader (19 May) supports this argument without recognising that there is no mechanism for car drivers to affect their hazard directly. The sensation generated by Ralph Nader's book, Unsafe at Any Speed, shows how much interest there is in automobile safety and at the same time how difficult it is to mount a campaign for it. The crucial difference between these 'widely accepted' hazards and hazards at work is that people at work have the organisation, numbers, and power to effect change. The use of this inappropriate comparison serves to blunt the force of the basic demand for adequate health and safety precautionary measures. It is shocking to realise that for the vast majority of fatal accidents at work the hazard is recognised and the safeguards are known (Accidents in Factories, HMSO 1971).

The fourth and most critical argument is the claim that adequate protection is simply too costly. Mr Jack Sheppard, managing director of Turner and Newhall, one of the biggest asbestos fibre processing companies in the world, testified at the Government Advisory Committee on Asbestos that the TUC demand of 0.2 fibres per cc would close the UK asbestos industry entirely. The forced choice between jobs and the environment has been one of the most effective methods of getting people to accept unsafe living and working conditions. This can only be fought effectively by supporting the health and safety struggles in other countries and trying to prevent the export of hazardous operations to countries with less stringent requirements.

The BSSRS Work Hazards Group disagrees completely with the management approach of protecting the process. First, not only do we ask if it is safe; we ask, who is it safe for? Present industrial safety considerations are confined at best to the general public and express little concern for the workforce itself. Second, we ask, who pays for the cost of safety? If government or industry decides not to pay, this does not mean that the cost vanishes. Far from it. The individual affected pays the cost in poor health lost wages and carly death. This is a shifting of cost. not the saving of money. In the Robas Report, accidents were estimated to cost the nation $0.8^{\prime \prime \prime}$ of the GNP. Third, in our practical work with trade unions we support the view that no matter how much information they may have, there is still a fundamental difference in perspective between the worker on the shop floor and the requitrements of management.

It is this conflict between those who control production and those who need safety, between those who assign the risks and those who are exposed to them that must be acknowledged. There is a continuing need for scientists and technologists who are prepared to acknowledge this conflict to help make available to working people the information they need to ensure their health and safety. 